\title{
Guava Leaves as Adsorbent for the Removal of Emerging Pollutant: Ciprofloxacin from Aqueous Solution
}

\author{
Chin-Inn Tay ${ }^{1}$ and Siew-Teng Ong ${ }^{1,2^{*}}$ \\ ${ }^{1}$ Faculty of Science, Universiti Tunku Abdul Rahman, \\ Jalan Universiti, Bandar Barat, 31900 Kampar, Perak, Malaysia \\ ${ }^{2}$ Centre for Biodiversity Research, Universiti Tunku Abdul Rahman, \\ Jalan Universiti, Bandar Barat, 31900 Kampar, Perak, Malaysia \\ *Corresponding author: ongst@utar.edu.my; ongst_utar@yahoo.com
}

Published online: 25 August 2019

To cite this article: Tay, C-I. \& Ong, S-T. (2019). Guava leaves as adsorbent for the removal of emerging pollutant: Ciprofloxacin from aqueous solution. J. Phys. Sci., 30(2), 137-156, https://doi.org/10.21315/jps2019.30.2.8

To link to this article: https://doi.org/10.21315/jps2019.30.2.8

\begin{abstract}
In this work, the feasibility of using guava leaves powder (GLP) as an adsorbent to remove ciprofloxacin (CIP) from aqueous solution was investigated. The effectiveness of GLP to remove CIP was studied under different experimental conditions. The optimum $\mathrm{pH}$ for the adsorption of CIP was found to be $\mathrm{pH}$ 4. The adsorption trend was rapid at the initial stage and equilibrium was achieved in 60 min. The percentage uptake of CIP decreased with increasing initial CIP concentration. The adsorption kinetics was found to conform well to the pseudo-second order kinetic model. Characterisation of GLP was carried out by using field emission scanning electron microscopy (FESEM), atomic force microscopy (AFM) and Fourier-transform infrared (FTIR) spectrophotometry. Both Langmuir and Freundlich isotherm models were applied to describe the equilibrium adsorption data of CIP onto GLP. The maximum adsorption capacity $\left(q_{m}\right)$ was found to be $232.56 \mathrm{mg} \mathrm{g}^{-1}$. By applying Plackett-Burman design, contact time and $\mathrm{pH}$ were found to be the influential parameters in affecting the uptake of CIP onto GLP.
\end{abstract}

Keywords: Ciprofloxacin, antibiotics, adsorbent, guava leaves, Plackett-Burman

\section{INTRODUCTION}

Antibiotic is any natural or synthetic chemical substance with the capability of killing or inhibiting the growth of microorganisms including bacteria and fungi. Apart from the fundamental application of antibiotics in improving human health, antibiotics are also useful in prevention and treatment of animal and plants 
infection. Besides, antibiotic has also been widely used in livestock farming to improve growth and feed efficiency. ${ }^{1,2}$ Several schemes are used to classify antibiotics which are based on type of activity (bacteriostatic vs. bactericidal), bacterial spectrum (broad vs. narrow), or chemical structure. One of the most useful classification schemes of antibiotics is based on their chemical structure. On the basis of structural classification, antibiotics that are being grouped within the same structural class exhibit similar activity spectra, allergic potential and toxicity. The main classes of antibiotics include beta-lactams, fluoroquinolones, aminoglycosides, macrolides and tetracyclines.

Thousands of tons of antibiotics are consumed in human and veterinary medicine and this trend seems to be increasing continuously. However, there is a growing concern on the impact of antibiotics on environment especially water resources. Due to the low biodegradability and incomplete metabolism, it has been estimated that about $30 \%-90 \%$ of the antibiotic dosage will be excreted in the unchanged form into the wastewater. The presence of antibiotic in aquatic environment has received extensive attention due to their potential role in development of antibiotic resistant bacteria. Apart from that, wastewater containing antibiotics also may pose deleterious effect on human health and ecosystems such as aquatic toxicity, genotoxicity and endocrine disruption. ${ }^{3}$

Ciprofloxacin (CIP) is a synthetic chemotherapeutic antibiotic categorised as the second-generation of fluoroquinolones. The IUPAC name of CIP is 1-cyclopropyl6-fluoro-4-oxo-7-piperazin-1-yl-quinolone-3-carboxylic acid and its molecular formula is $\mathrm{C}_{17} \mathrm{H}_{18} \mathrm{FN}_{3} \mathrm{O}_{3}$. The presence of CIP in wastewater has been detected at various concentrations, ranging from $<1 \mu \mathrm{g} \mathrm{1^{-1 }}$ to higher than $30 \mathrm{mg} \mathrm{1}^{-1}$. $^{4-6}$ According to the Center for Disease Dynamics, Economics and Policy, CIP is one of the most commonly prescribed antibiotics in the United States and therefore the removal of CIP from water sources is indeed a critical and emerging issue.

Psidium guajava or guava which comes from the Myrtaceae family is a plant commonly found in a tropical country like Malaysia and in fact, the world's largest pink guava plantation is located in Malaysia. From some of the previously reported works, the adsorption results have shown the potential of guava leaves in removing pollutants such as Brilliant Green and As(III) with the adsorption capacity of $1.075 \mathrm{mg} \mathrm{g}^{-1}$ and $1.06 \mathrm{mg} \mathrm{g}^{-1}$, respectively.,8 Therefore, in this work, the suggested economical approach to remove CIP from aqueous solution is through adsorption due to its attractive features such as simplicity in terms of design and insensitivity towards toxic substances. Besides, as guava leaves are available abundantly in Malaysia, therefore, they can be used extensively for biosorption of CIP and offers a cost effective and environmentally friendly treatment method. 
The conventional way of investigating a process by maintaining other variables involved at a non-specific constant level does not give well description on the combined effect of all the variables involved. ${ }^{9}$ There are several limitations of the conventional methods including being time consuming as well as the inability to determine the optimal conditions. ${ }^{10}$ Hence, in this study, these limitations were overcome through the application of Plackett-Burman design. Plackett-Burman design consists of a specific fraction $2^{\mathrm{P}}$ factorial design, where the factor levels are represented by +1 (if the level of factor is high) and -1 (if the level of factor is low). By adopting the factorial design in studying a process, the effect of each parameter can be determined. This will greatly reduce the number of experiments involved and make the process less time consuming. Besides, most of the affecting parameters can be optimised collectively. ${ }^{9-11}$

\section{EXPERIMENTAL}

\subsection{Adsorbent}

Guava leaves were collected from Psidium guajava tree and washed thoroughly with distilled water in order to remove dust and other impurities. The leaves were then dried in oven at $70^{\circ} \mathrm{C}$ overnight. The dried leaves were grinded into powder form and passed through a $1 \mathrm{~mm}$ sieve. The dried powder was then immersed in $1 \% \mathrm{w} / \mathrm{v} \mathrm{NaOH}$ solution with continuous stirring for $3 \mathrm{~h}$ for bleaching purpose. Thereafter, it was filtered and washed with distilled water until neutral $\mathrm{pH}$ was reached. The treated guava leaves powder (GLP) was dried at $70^{\circ} \mathrm{C}$ for $24 \mathrm{~h}$ and stored into the air tight container for further experimental use.

\subsection{Adsorbates}

CIP was purchased from Acros Organics with 98\% purity and used without any further purification. Standard solution of $100 \mathrm{mg} \mathrm{l}^{-1}$ CIP was prepared as stock solution. The desired concentration of CIP solution was then obtained by performing dilutions from the stock solution. These solutions were wrapped with aluminium foil and kept in the dark condition to prevent degradation.

\subsection{Instrumental and Characterisation Analysis}

The functional groups that are present on the GLP were identified using Perkin Elmer FTIR, Spectrum RX1. Both GLP (before and after adsorption) were subject to FTIR analysis and the wavenumber used was in the range of $400-4000 \mathrm{~cm}^{-1}$. FESEM (JEOL FESEM JSM 6701F) was used to study the surface morphology of GLP before adsorption and after adsorption. The instrument was operated at 
emission current of $2.0 \mathrm{kV}$ with the working distance of $6.0 \mathrm{~mm}$. For the surface topography analysis, atomic force microscope (AFM, Park System, XE-70) was employed to study the differences before and after the adsorption process in the GLP.

\subsection{Batch Study}

In each experiment, $0.02 \mathrm{~g}$ GLP was added to $25 \mathrm{ml}$ of CIP solution in a $50 \mathrm{ml}$ centrifuge tube. The centrifuge tube was then placed on the orbital shaker and agitated at $150 \mathrm{rpm}$ for $4 \mathrm{~h}$. After agitation, the samples were centrifuged at $3000 \mathrm{rpm}$ for 2 min using Eppendorf ${ }^{\mathrm{TM}}$ Model 5430 Microcentrifuge to separate the solid and aqueous phase. The same experimental conditions were employed throughout the study unless otherwise stated. The batch adsorption experiments were performed in duplicates to obtain an average value. The concentration of CIP in supernatant solution was determined at $\lambda_{\max }=274 \mathrm{~nm}$, which is the characteristic wavelength of CIP by using a single beam UV-visible spectrophotometer (Shimadzu UVmini-1240).

The percentage uptake of CIP solution was calculated using the Equation 1:

$$
\% \text { Uptake }=\frac{\mathrm{C}_{\mathrm{o}}-\mathrm{C}_{\mathrm{t}}}{\mathrm{C}_{\mathrm{o}}} \times 100 \%
$$

where $\mathrm{C}_{\mathrm{o}}$ is the initial concentration of CIP $\left(\mathrm{mg} \mathrm{l}^{-1}\right)$ and $\mathrm{C}_{\mathrm{t}}=$ concentration of CIP at time $\mathrm{t}\left(\mathrm{mg} \mathrm{l}^{-1}\right)$.

\subsubsection{Effect of $\mathrm{pH}$}

The desired $\mathrm{pH}$ of CIP solution was adjusted to the range of 2 to 10 by adding dilute $\mathrm{HCl}$ or $\mathrm{NaOH}$ dropwise before the addition of the adsorbent.

\subsubsection{Effect of initial CIP concentrations and contact time}

CIP solutions with $20 \mathrm{mg}^{-1}, 30 \mathrm{mg}^{-1}$ and $40 \mathrm{mg} \mathrm{l}^{-1}$ were used in this parameter and for each concentration, the sample solutions were collected at regular time intervals which were $5 \mathrm{~min}, 10 \mathrm{~min}, 15 \mathrm{~min}, 30 \mathrm{~min}, 60 \mathrm{~min}, 120 \mathrm{~min}, 180 \mathrm{~min}$, $240 \mathrm{~min}$ and $300 \mathrm{~min}$.

\subsubsection{Sorption isotherm}

Sorption isotherms of CIP were obtained by changing the initial concentrations of CIP, starting at $20.0 \mathrm{mg} \mathrm{l}^{-1}$ to $50.0 \mathrm{mg} \mathrm{l}^{-1}$. In each concentration, $0.02 \mathrm{~g}$ of GLP in $25 \mathrm{ml}$ of CIP solution was agitated at $150 \mathrm{rpm}$ for $4 \mathrm{~h}$. 


\subsection{Plackett-Burman Design}

Plackett-Burman design is a statistical approach used to determine the significant variables that will influence the percentage uptake of CIP. Three parameters which included $\mathrm{pH}$, initial concentration and contact time were tested and 12 experimental designs were generated. All experimental runs were performed in duplicate and average values were taken. Design-Expert Version 7.1.3.1 is the computer software used to analyse the statistical data and to generate the experimental designs.

\section{RESULTS AND DISCUSSION}

\subsection{Instrumental Analysis}

\subsubsection{FTIR}

Figure 1 shows the infrared spectra of GLP before and after adsorption. By referring to the FTIR spectrum of GLP before adsorption, the broad peak with high intensity at $3409 \mathrm{~cm}^{-1}$ resulted from the stretching vibration of O-H group. Overlapping of stretching vibration of $\mathrm{N}-\mathrm{H}$ group with the broad O-H peak might occur as these occur at almost the same region. The peak appearing at $2927 \mathrm{~cm}^{-1}$ was due to stretching vibration of $\mathrm{sp}^{3} \mathrm{C}-\mathrm{H} .{ }^{12}$ In addition, the peak with weak intensity at $1427 \mathrm{~cm}^{-1}$ was attributed to the $\mathrm{C}=\mathrm{C}$ stretching vibration. After the adsorption process, the spectrum illustrates almost the same peaks. This could be due to the limitations in the sensitivity of the instrument. Besides, as the nature of the process is mainly due to adsorption, which is a surface chemistry process, therefore it is acceptable that the FTIR spectra should resemble each other. This agreed well with some of the previous findings in the adsorption process involving dyes. ${ }^{13,14}$ 


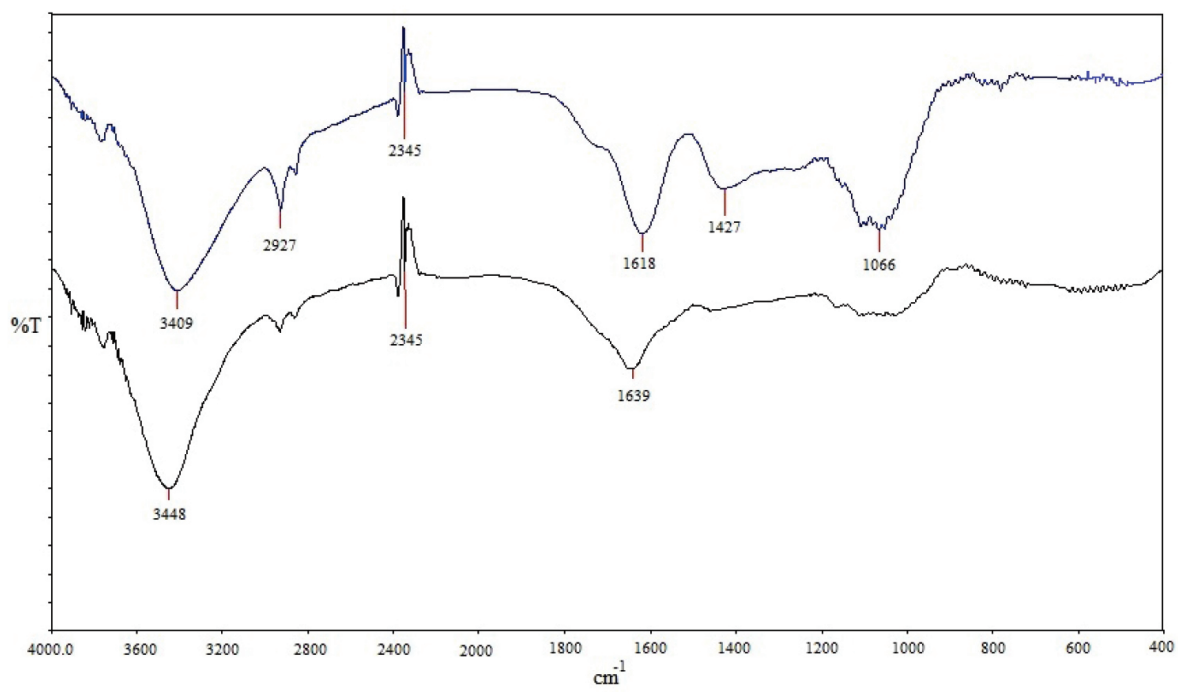

Figure 1: FTIR spectrum of GLP before adsorption (blue) and GLP after adsorption (black).

\subsubsection{Surface characterisation}

The FESEM micrographs of the GLP before and after adsorption of CIP were shown in Figure 2. Based on these micrographs, both GLP before and after adsorption have a rough and uneven surface. The surface texture of GLP after adsorption appeared to be rougher by comparing with that before adsorption. This can be associated with the adhesion of CIP on GLP. As shown from the micrographs, it is evident that GLP is a non-porous material due to the absence of pores and cavities.
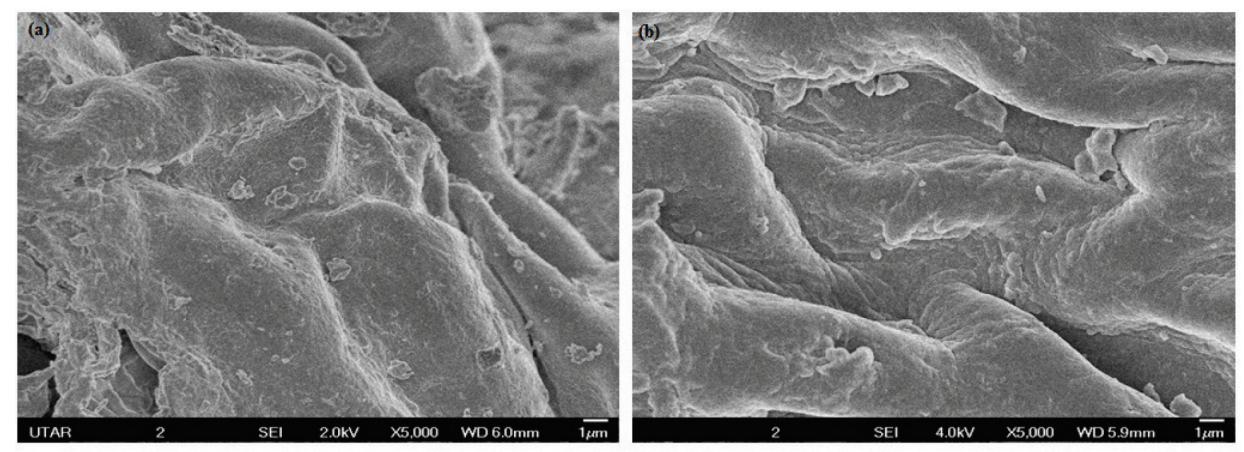

Figure 2: FESEM micrograph of GLP with the magnification of 5000X for (a) before adsorption of CIP, and (b) after adsorption of CIP. 
In order to elucidate the changes on the surface topography of the GLP before and after CIP adsorption, AFM analysis was carried out. The analysis was performed using the contact mode by AFM whereby the tip scans the sample in close contact with the surface on a $10 \times 10 \mu \mathrm{m}^{2}$ area. Figure 3 shows the surface topography of GLP before and after adsorption, respectively. Based on Figure 3(a), a smooth flat plateau-like structure was observed on the surface topography of GLP before adsorption while a rough and uneven structure was observed for the GLP after adsorption, shown in Figure 3(b). Colour mapping of these images was used for displaying the data where light colour indicates high features or high topography and lower topography was shown by darker colour. As illustrated from the images, higher topography was obtained after the adsorption of CIP and this is an expected phenomenon as the surface has become more intense due to the adhesion and saturation of CIP molecules.
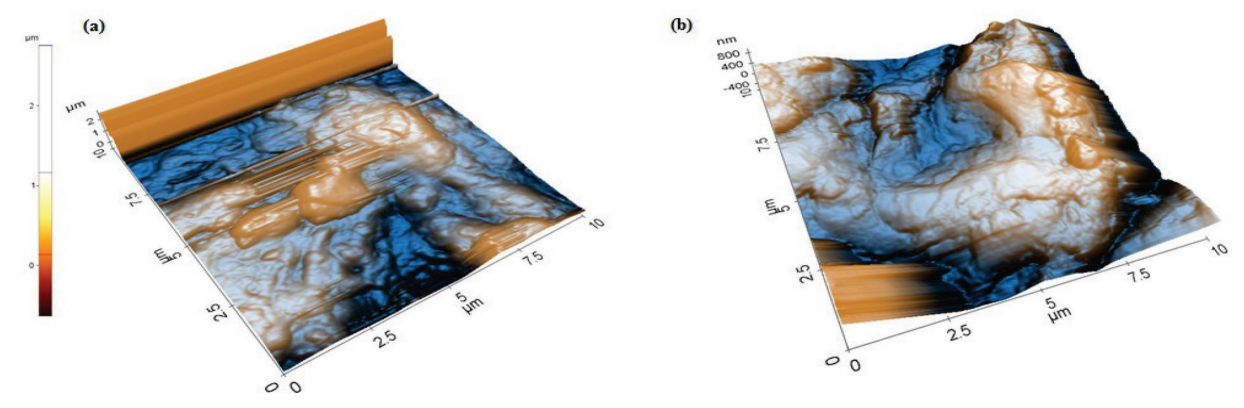

Figure 3: AFM colour image of GLP for (a) before CIP adsorption process, and (b) after CIP adsorption process.

\subsection{Effect of Initial pH of CIP Solution}

In most of the adsorption process, the efficiency of the uptake is strongly $\mathrm{pH}$ dependent because the $\mathrm{pH}$ of the solution affects the degree of ionisation of adsorbates as well as the surface charge of the adsorbent. CIP forms different ionic species, namely anionic, cationic and zwitterionic under different $\mathrm{pH}$ values. At $\mathrm{pH}<5.90$, the cationic form $\left(\mathrm{CIP}^{+}\right)$is dominant due to the protonation of the secondary amine on the piperazine group. CIP exists in the zwitterionic form $\left(\mathrm{CIP}^{ \pm}\right)$ when solution $\mathrm{pH}$ is between 5.90 and 8.89 . As the $\mathrm{pH}$ of the solution increase to greater than 8.89 , deprotonation from the secondary amine on the piperazine group took place and caused the formation of anionic form of CIP ${ }^{15}$ Apart from that, the $\mathrm{pH}$ of zero point charge $\left(\mathrm{pH}_{\mathrm{pzc}}\right)$ of GLP was also determined and found to be 7.12. The $\mathrm{pH}_{\mathrm{pzc}}$ refers to the $\mathrm{pH}$ value at which the adsorbent surface has net zero charge or is electrically neutral. The surface of the adsorbent possess a positive charge 
when $\mathrm{pH}<\mathrm{pH}_{\mathrm{pzc}}$ while the adsorbent surface gets negatively charged when $\mathrm{pH}$ greater than 7.12 .

Figure 4 shows the influence of $\mathrm{pH}$ on adsorption of CIP onto GLP, ranging from $\mathrm{pH} 2$ to 10. The percentage uptake of CIP was low at $\mathrm{pH} 2$ but reach a maximum point $(67.89 \%)$ at $\mathrm{pH}$ 4. The percentage uptake of CIP declined with further increase in $\mathrm{pH}$, which reached a lowest percentage uptake of $22.35 \%$ at $\mathrm{pH} 10$. A similar result was reported in the adsorption of CIP onto water hyacinth derived biochar. ${ }^{16}$

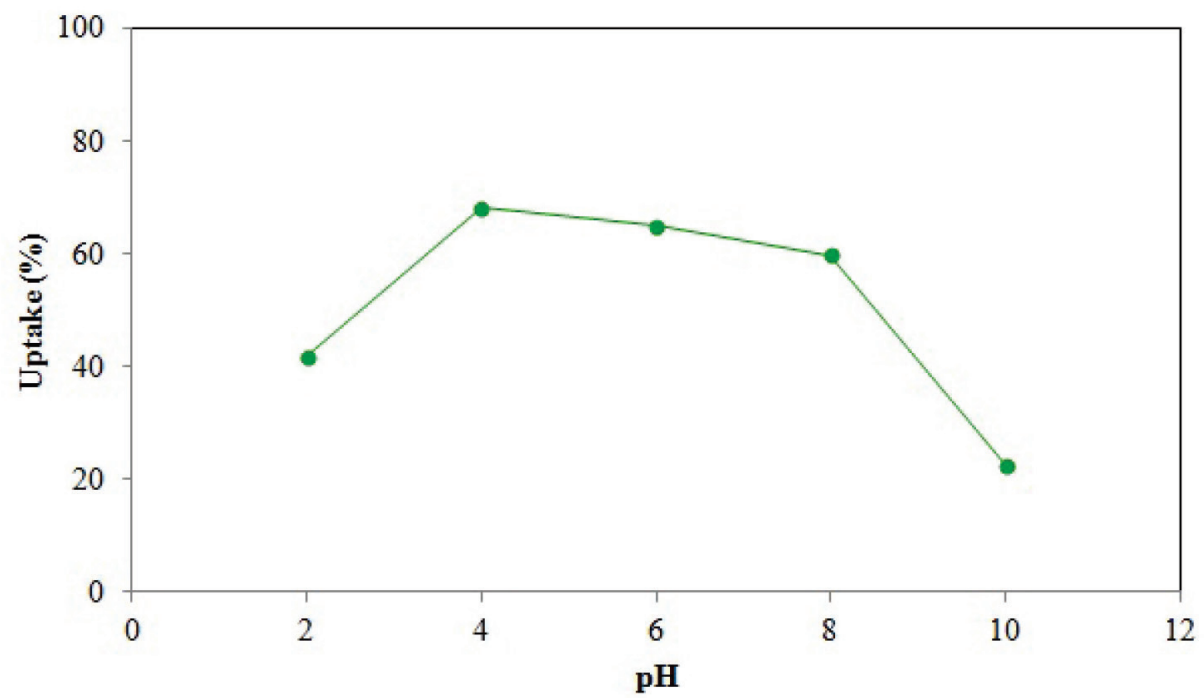

Figure 4: Effect of $\mathrm{pH}$ for CIP adsorption onto GLP.

The fairly low adsorption observed at extremely low and high $\mathrm{pH}$ was attributed to the great repulsive forces between the adsorbent surface and CIP molecule. As $\mathrm{pH}$ increased, the concentration of $\mathrm{H}^{+}$decreased and the electrostatic repulsive interaction between CIP molecule and surface of adsorbent had greatly reduced thus leading to highest percentage uptake of CIP at $\mathrm{pH} 4$. In the $\mathrm{pH}$ range of 5.90 to 8.89 , electrostatic interaction took place between the positively charged amine group in the zwitterionic form of CIP and the carbon-oxygen group on the adsorbent surface which possess negative charge. Nevertheless, there was still a certain degree of repulsion between negatively charged adsorbent surface and the negatively charged carboxylate group in CIP zwitterion, which significantly reduced the percentage uptake of CIP. ${ }^{17}$ Hence, it can be deduced that electrostatic force is the dominant interaction that can control the adsorption of CIP beyond the $\mathrm{pK}_{\mathrm{a}}$ range. 


\subsection{Effect of Initial CIP Concentration and Contact Time}

The primary goal to investigate the effect of contact time and initial concentration is to identify the equilibrium time for maximum adsorption. Figure 5 shows the effect of contact time and initial concentration on the percentage uptake of CIP using three different concentrations, $20 \mathrm{mg} \mathrm{l}^{-1}, 30 \mathrm{mg} \mathrm{l}^{-1}$ and $40 \mathrm{mg}^{-1}$ of CIP. A decrease in percentage uptake of CIP was observed when initial CIP concentration was increased. This is most likely due to the increase number of CIP molecules per unit volume which subsequently causes the binding sites on the adsorbent to become fast saturated and exhausted. For all the studied concentrations, a rapid uptake was observed at the beginning of the adsorption process from 0 min until $60 \mathrm{~min}$ after that adsorption rate became slower before its equilibrium stage was reached. Similar trend was reported in the removal of ciprofloxacin hydrochloride by using sawdust. ${ }^{18}$ The fast uptake in the beginning can be associated with the rapid adhering of CIP molecules onto the adsorbent's surface due to the electrostatic attraction.

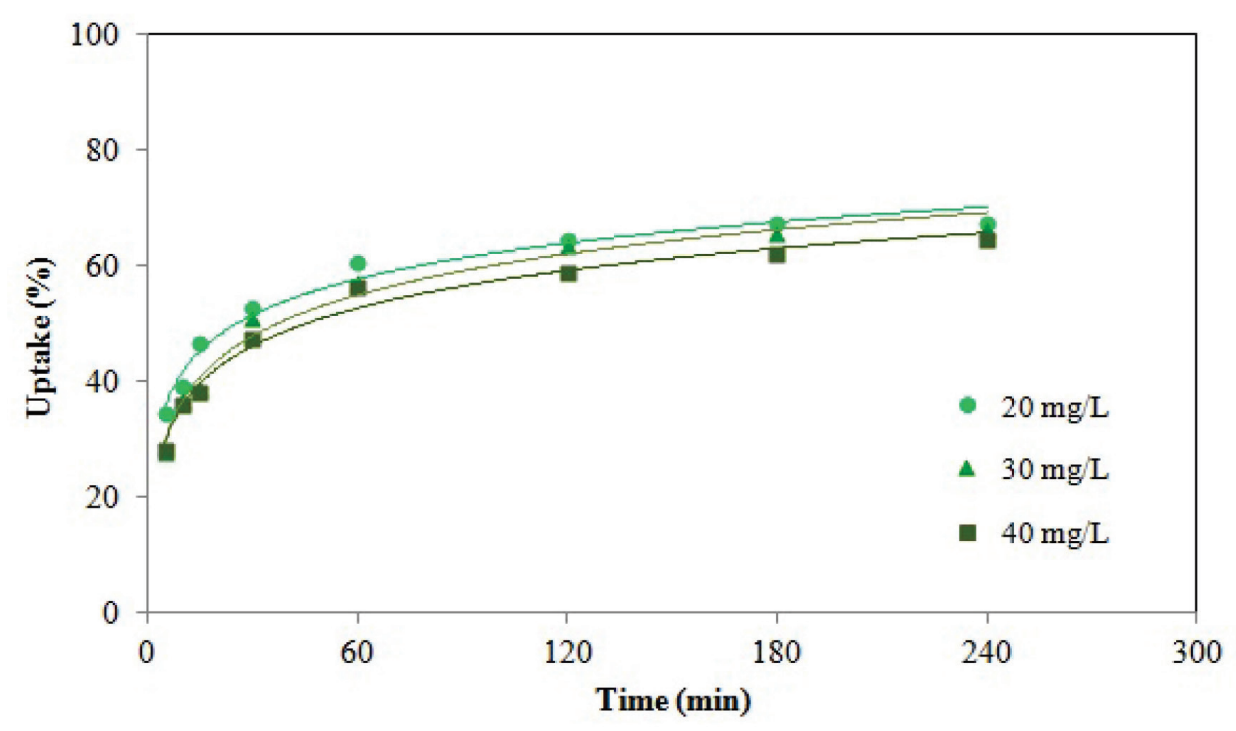

Figure 5: Effect of contact time and initial CIP concentrations onto GLP.

Besides, there are also more vacant binding sites that are available at the initial stage. Therefore, a powerful driving force can be generated and the resistance of mass transfer between solid and aqueous phases can be overcome by the molecules. ${ }^{10}$ The following gradual adsorption rate may be attributed to the intraparticle diffusion in which the adsorbate molecules tend to diffuse into the 
inner sites of adsorbent. Ultimately, the adsorption process reached its equilibrium stage due to the saturation of adsorbent's binding sites with adsorbate particles.

\subsection{Kinetic Studies}

In wastewater treatment, the adsorption kinetic study is essential for the proper and well-designed adsorption process as it allows the understanding of reaction pathways and adsorption mechanisms. ${ }^{19}$ In order to analyse the adsorption data, two widely used kinetic models which are pseudo-first order and pseudo-second order kinetic models were applied. ${ }^{19,20}$ Linear correlation coefficient $\left(\mathrm{R}^{2}\right)$ is the parameter used to decide the best fit model.

\subsubsection{Pseudo-first order kinetic model}

According to Lagergren, the equation of pseudo-first order kinetic model is defined as: ${ }^{20}$

$$
\frac{d q_{t}}{d t}=K_{1}\left(q_{e}-q_{t}\right)
$$

where $\mathrm{q}_{\mathrm{t}}$ is the amount of adsorbate adsorbed at time $\mathrm{t}\left(\mathrm{mg} \mathrm{g}^{-1}\right), \mathrm{q}_{\mathrm{e}}$ is the amount of adsorbate adsorbed at equilibrium $\left(\mathrm{mg} \mathrm{g}^{-1}\right)$, and $\mathrm{K}_{1}$ is rate constant of pseudo first-order kinetics $\left(\mathrm{min}^{-1}\right)$.

The integration of Equation 2 using the boundary conditions: $\left.\mathrm{q}_{\mathrm{t}}\right|_{\mathrm{t}=0}=0$ and $\left.\mathrm{q}_{\mathrm{t}}\right|_{\mathrm{t}=\mathrm{t}}=\mathrm{q}_{\mathrm{t}}$, gives:

$$
\log \left(\mathrm{q}_{e}-\mathrm{q}_{t}\right)=\log \mathrm{q}_{e}-\frac{\mathrm{K}_{1}}{2.303} \mathrm{t}
$$

The values of $\mathrm{K}_{1}$, calculated and experimental values of $\mathrm{q}_{\mathrm{e}}$ and also the linear correlation coefficient values $\left(\mathrm{R}^{2}\right)$ from pseudo-first order kinetic plots were shown in Table 1. It is quite evident that there is a huge difference between the experimental values of $\mathrm{q}_{\mathrm{e}}$ compared to the calculated ones based on pseudo-first order model. Apart from that, the correlation coefficients based on pseudo-first order model at various concentrations were in lower than those obtained from pseudo-second order model. 


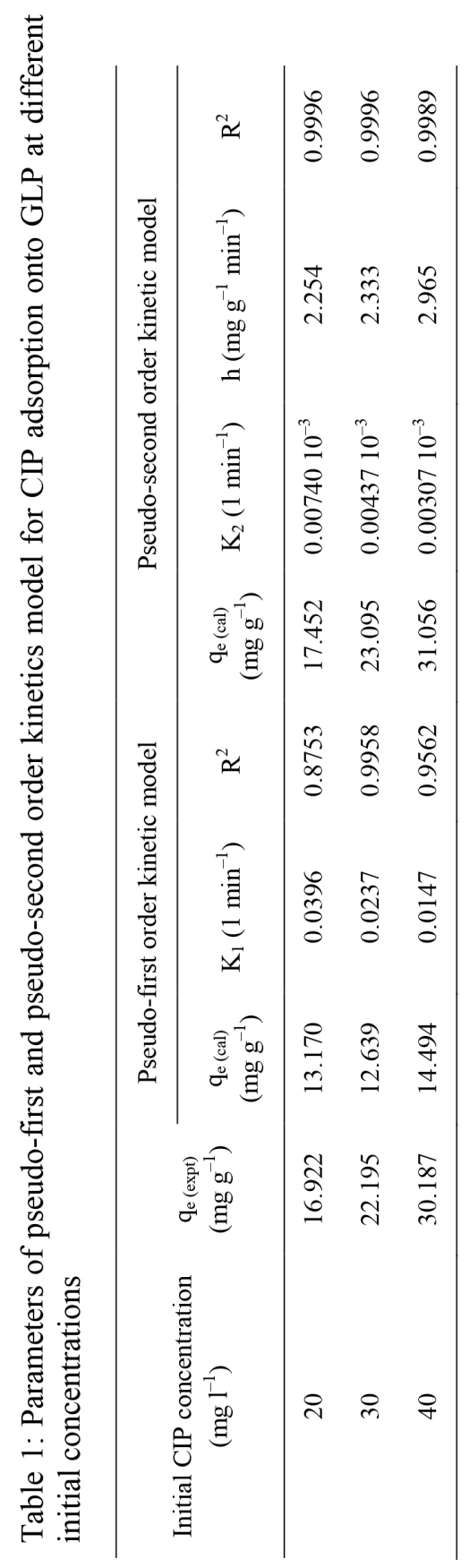




\subsubsection{Pseudo-second order kinetic model}

In pseudo-second order kinetic model, assumption was made that chemisorption is the rate limiting step of the adsorption process. ${ }^{19}$ The pseudo-second order kinetic model is expressed as:

$$
\frac{\mathrm{dq}}{\mathrm{dt}}=\mathrm{K}_{2}\left(\mathrm{q}_{e}-\mathrm{q}_{t}\right)^{2}
$$

where $\mathrm{K}_{2}$ is the rate constant of pseudo second-order kinetics $\left(\mathrm{g} \mathrm{mg} \mathrm{min}{ }^{-1}\right)$.

The integration of Equation 4 using the boundary conditions: $\left.\mathrm{q}_{\mathrm{t}}\right|_{\mathrm{t}=0}=0$ and $\left.\mathrm{q}_{\mathrm{t}}\right|_{\mathrm{t}=\mathrm{t}}=\mathrm{q}_{\mathrm{t}}$, gives:

$$
\frac{1}{\mathrm{q}_{e}-\mathrm{q}_{t}}=\frac{1}{\mathrm{q}_{e}}+\mathrm{K}_{2} \mathrm{t}
$$

Rearrangement of Equation 5 into linear form gives:

$$
\frac{\mathrm{t}}{\mathrm{q}_{t}}=\frac{1}{\mathrm{~K}_{2} \mathrm{q}_{e}^{2}}+\frac{\mathrm{t}}{\mathrm{q}_{e}}
$$

Initial sorption rate, $\mathrm{h}\left(\mathrm{mg} \mathrm{g}^{-1} \mathrm{~min}^{-1}\right)$ can be determined by using Equation 7 :

$$
\mathrm{h}=\mathrm{K}_{2} \mathrm{q}_{e}^{2}
$$

Figure 6 shows the linear plots of $\mathrm{t} / \mathrm{q}_{\mathrm{t}}$ against $\mathrm{t}$ at different initial CIP concentrations (20 $\mathrm{mg} \mathrm{l}^{-1}, 30 \mathrm{mg} \mathrm{l}^{-1}$ and $40 \mathrm{mg} \mathrm{l}^{-1}$ ). Values of $\mathrm{K}_{2}$ and $\mathrm{q}_{\mathrm{e}}$ were obtained by referring to the values of slope and intercept of the plots. These values were then used to calculate the initial sorption rate, $\mathrm{h}\left(\mathrm{mg} \mathrm{g}^{-1} \mathrm{~min}^{-1}\right)$ by using Equation 7. Table 1 presents the parameters of pseudo-second order plots such as values of $K_{2}, R^{2}$ and calculated and experimental $\mathrm{q}_{\mathrm{e}}$. The values of calculated $\mathrm{q}_{\mathrm{e}}$ from the pseudo-second order kinetic model agreed well with those obtained experimentally. Furthermore, all the pseudo-second order plots were perfectly linear as $\mathrm{R}^{2}$ values above 0.998 were obtained, which are close to unity. This shows that pseudo-second order kinetic model provides a good correlation to the adsorption data and suggests that the rate-limiting step of adsorption process of CIP onto GLP is chemisorption. 


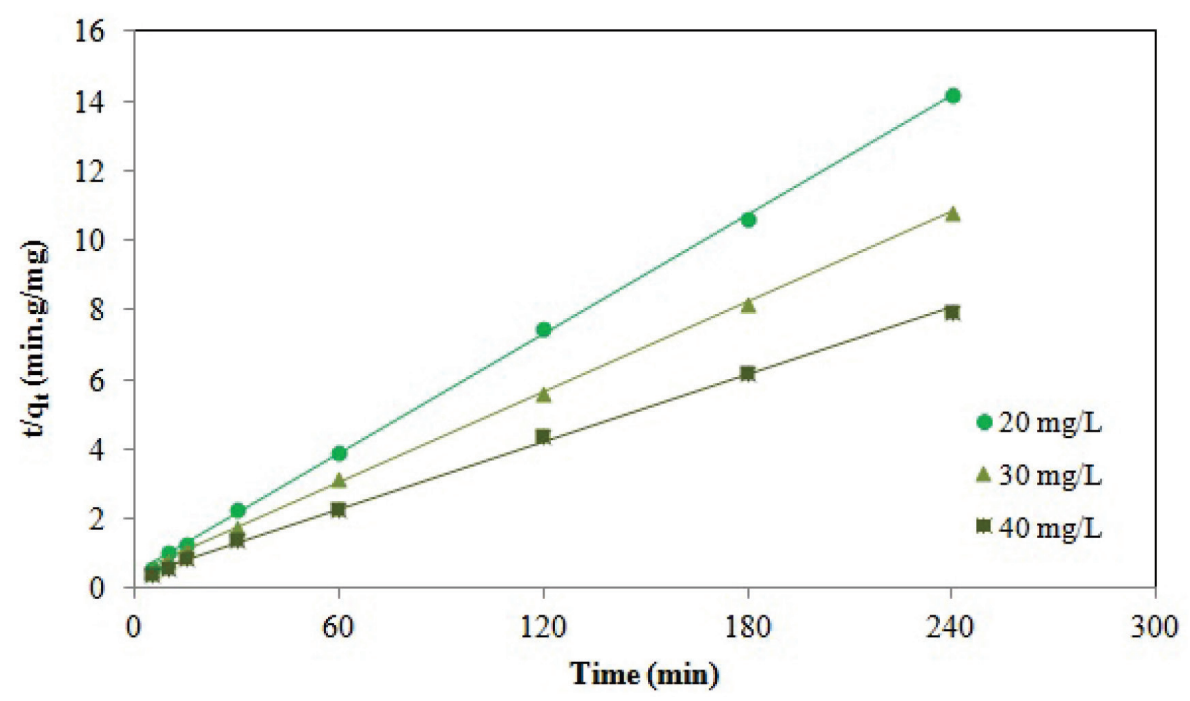

Figure 6: Pseudo-second order kinetics of CIP adsorption onto GLP.

Similar findings reported on the best fit model for the adsorption process based on pseudo-second order kinetic model equation including adsorption of CIP onto montmorillonite, ordered mesoporous carbon (OMC) and bamboo-based carbon (BC), and enrofloxacin and ofloxacin onto bamboo biochar. ${ }^{15,21,22}$

\subsection{Sorption Isotherm}

In this study, Langmuir and Freundlich isotherm models were applied to analyse the equilibrium data. Evaluation on the adsorption capacity, type of coverage and rate constants can be done by using these adsorption isotherms. Values of the linear correlation coefficient, $\mathrm{R}^{2}$ were used to determine the applicability of the isotherm equation.

\subsubsection{Langmuir isotherm model}

The Langmuir isotherm model is expressed as:

$$
\mathrm{q}_{e}=\mathrm{q}_{\mathrm{m}} \frac{\mathrm{K}_{\mathrm{L}} \mathrm{C}_{e}}{1+\mathrm{K}_{\mathrm{L}} \mathrm{C}_{e}}
$$

where $\mathrm{q}_{\mathrm{e}}$ is the amount of adsorbate adsorbed at equilibrium ( $\left.\mathrm{mg} \mathrm{g}^{-1}\right), \mathrm{q}_{\mathrm{m}}$ is the maximum adsorption capacity $\left(\mathrm{mg} \mathrm{g}^{-1}\right), \mathrm{K}_{\mathrm{L}}$ is the Langmuir adsorption constant $\left(1 \mathrm{mg}^{-1}\right)$, and $\mathrm{C}_{\mathrm{e}}$ is the concentration of adsorbate at equilibrium $\left(\mathrm{mg} \mathrm{l}^{-1}\right)$. 
The rearrangement of Equation 8 into linear form gives:

$$
\frac{1}{\mathrm{q}_{e}}=\frac{1}{\mathrm{q}_{\mathrm{m}} \mathrm{K}_{\mathrm{L}} \mathrm{C}_{\mathrm{e}}}+\frac{1}{\mathrm{q}_{\mathrm{m}}}
$$

A plot of $1 / q_{e}$ versus $1 / C_{e}$ (Figure 7 ) with a high linear correlation coefficient of 0.9965 was obtained, indicating Langmuir isotherm shows a good correlation with the equilibrium data. The maximum adsorption capacity of CIP by GLP obtained was $232.56 \mathrm{mg} \mathrm{g}^{-1}$ whereas the $\mathrm{K}_{\mathrm{L}}$ obtained from the plot was $0.0111 \mathrm{mg}^{-1}$.

A dimensionless separation factor $\left(\mathrm{R}_{\mathrm{L}}\right)$ is defined as:

$$
\mathrm{R}_{\mathrm{L}}=\frac{1}{1+\mathrm{K}_{\mathrm{L}} \mathrm{C}_{\mathrm{o}}}
$$

where $\mathrm{C}_{0}$ is the initial concentration of CIP $\left(\mathrm{mg} \mathrm{l}^{-1}\right)$.

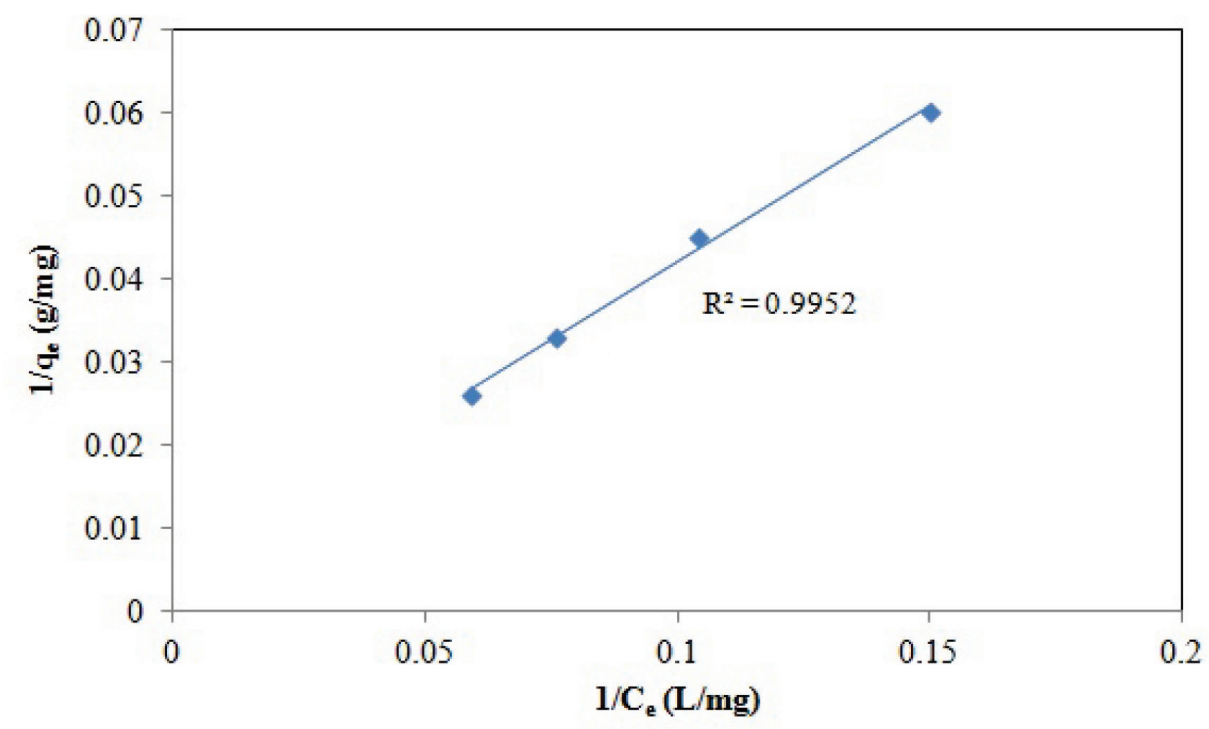

Figure 7: Langmuir isotherm for the adsorption of CIP onto GLP.

The calculated $R_{L}$ values can be used to describe the nature of the adsorption process whereby $\mathrm{R}_{\mathrm{L}}>1$, unfavourable; $\mathrm{R}_{\mathrm{L}}=1$, linear; $0<\mathrm{R}_{\mathrm{L}}<1$, favourable; $\mathrm{R}_{\mathrm{L}}=0$, irreversible. For the initial CIP concentrations of $20 \mathrm{mg} \mathrm{1}^{-1}, 30 \mathrm{mg}^{-1}$, $40 \mathrm{mg} \mathrm{l}^{-1}$ and $50 \mathrm{mg}^{-1}$, the calculated $\mathrm{R}_{\mathrm{L}}$ values for GLP were $0.8174,0.7652$, 0.7054 and 0.6535 , respectively. All the $R_{L}$ values were within the range of $0<R_{L}$ $<1$ which indicates the favourable adsorption of CIP onto GLP. 


\subsubsection{Freundlich isotherm model}

Freundlich isotherm model assumes that adsorption occurs on heterogeneous surface and the stronger binding sites are being occupied first. The binding strength will then weaken due to the increase in rate at which the sites are occupied. The mathematical expression of the Freundlich isotherm model is defined as:

$$
\mathrm{q}_{e}=\mathrm{K}_{\mathrm{F}} \mathrm{C}_{\mathrm{E}}^{1 / \mathrm{n}}
$$

where $\mathrm{K}_{\mathrm{F}}$ is the Freundlich constant for adsorption capacity $\left(\mathrm{mg} \mathrm{g}^{-1}\right)$, and $\mathrm{n}$ is the Freundlich constant for adsorption intensity.

Equation 11 can be rearranged into linear form as follow:

$$
\log \mathrm{q}_{\mathrm{e}}=\log \mathrm{K}_{\mathrm{F}}+\frac{1}{\mathrm{n}} \log \mathrm{C}_{\mathrm{e}}
$$

Figure 8 shows the graph of $\log \mathrm{q}_{\mathrm{e}}$ against $\log \mathrm{C}_{\mathrm{e}}$ with a high $\mathrm{R}^{2}$ value of 0.9981 . This indicates that the equilibrium data was described well by Freundlich isotherm model. The value of $n$ and $\mathrm{K}_{\mathrm{F}}$ were 2.13 and 2.94 , respectively. The $\mathrm{n}$ value which lies in the range of 1 to 10 again indicates the favourable adsorption nature of CIP onto GLP. ${ }^{23}$

The linear correlation coefficients and parameters obtained from the Langmuir and Freundlich isotherm plots were listed in Table 2. Based on the results, it can be concluded that the equilibrium data fitted well into both Langmuir and Freundlich isotherm models as the $\mathrm{R}^{2}$ value obtained were high and close to unity. This suggests that both homogeneous and heterogeneous adsorption process occur simultaneously. 


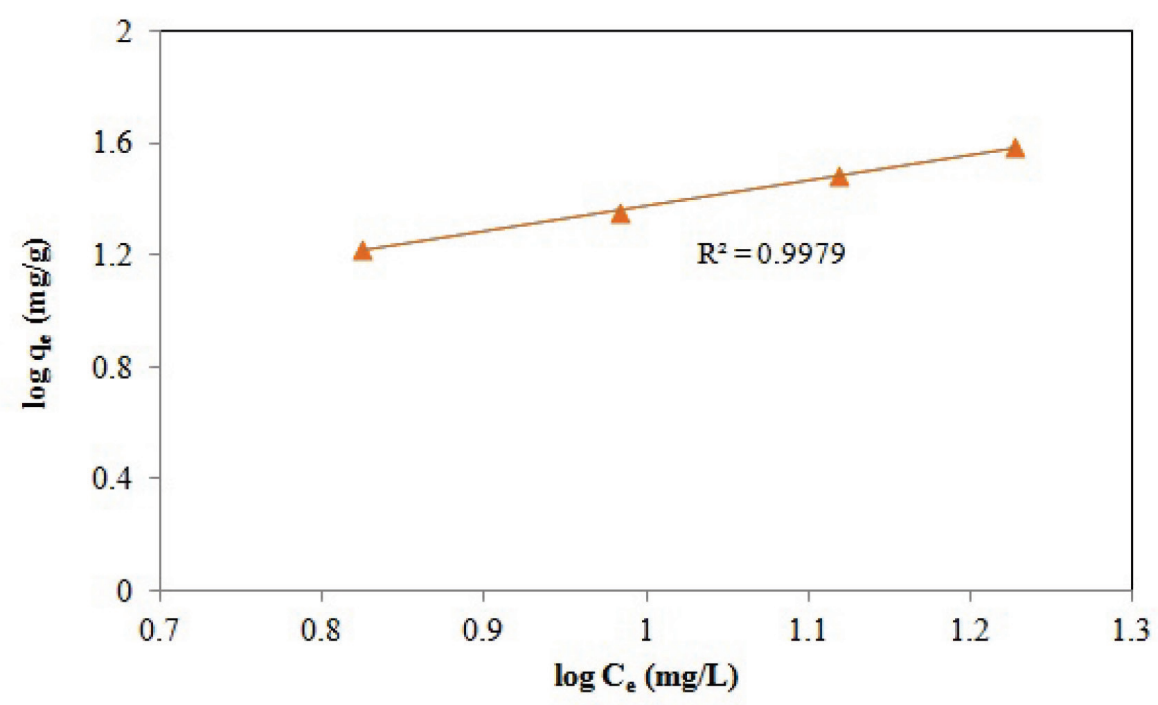

Figure 8: Freundlich isotherm for the adsorption of CIP onto GLP.

Table 2: Isotherm parameters and correlation coefficients for the adsorption of CIP onto GLP.

\begin{tabular}{llllll}
\hline & \multicolumn{3}{c}{ Langmuir isotherm } & \multicolumn{3}{c}{ Freundlich isotherm } \\
\hline $\mathrm{K}_{\mathrm{L}}\left(1 \mathrm{mg}^{-1}\right)$ & $\mathrm{q}_{\mathrm{m}}\left(\mathrm{mg} \mathrm{g}^{-1}\right)$ & $\mathrm{R}^{2}$ & $\mathrm{~K}_{\mathrm{F}}\left(\mathrm{mg} \mathrm{g}^{-1}\right)$ & $\mathrm{n}$ & $\mathrm{R}^{2}$ \\
0.011 & 232.56 & 0.9965 & 2.94 & 2.13 & 0.9981 \\
\hline
\end{tabular}

\subsection{Plackett-Burman Design}

In this study, Plackett-Burman design, a statistical analysis was employed to evaluate and identify important parameters in affecting the percentage uptake of CIP onto GLP. The tested parameters include contact time, $\mathrm{pH}$ and initial CIP concentrations. Table 3 illustrates all the experimental designs and the results, whereas Table 4 presents the results of analysis of variance (ANOVA) of all the CIP solutions. Significant model terms were indicated by the value of $($ Prob $>$ F $)<0.05$. The model F-value and $($ Prob $>$ F) value were 35.25 and $<0.0001$, respectively, which indicate that the model was significant. 
Table 3: Plackett-Burman experimental design and the predicted and observed response for the adsorption of CIP onto GLP.

\begin{tabular}{cccccc}
\hline \multirow{2}{*}{$\begin{array}{c}\text { Experimental } \\
\text { run }\end{array}$} & $\begin{array}{c}\text { Initial } \\
\text { concentration } \\
\left(\mathrm{mg} \mathrm{l}^{-1}\right)\end{array}$ & $\mathrm{pH}$ & $\begin{array}{c}\text { Contact time } \\
(\mathrm{min})\end{array}$ & $\begin{array}{c}\text { Observed } \\
\text { response (\%) }\end{array}$ & $\begin{array}{c}\text { Predicted } \\
\text { response (\%) }\end{array}$ \\
\cline { 2 - 4 } 1 & 20 & 2 & 5 & 9.62 & 9.39 \\
2 & 20 & 2 & 240 & 41.70 & 36.51 \\
3 & 20 & 10 & 240 & 22.35 & 24.83 \\
4 & 40 & 2 & 5 & 8.23 & 10.43 \\
5 & 40 & 2 & 240 & 39.49 & 37.54 \\
6 & 40 & 10 & 240 & 28.03 & 25.86 \\
\hline
\end{tabular}

Table 4: Regression analysis (ANOVA) for the adsorption of CIP onto GLP.

\begin{tabular}{lllllll}
\hline Source & $\begin{array}{l}\text { Sum of } \\
\text { squares }\end{array}$ & $\begin{array}{l}\text { Degree of } \\
\text { freedom }\end{array}$ & $\begin{array}{l}\text { Mean } \\
\text { square }\end{array}$ & F value & $\begin{array}{l}\text { p-value } \\
\text { Prob }>\text { F }\end{array}$ & Description \\
\hline Model & 2617.87 & 3 & 872.62 & 35.25 & $<0.0001$ & Significant \\
A - pH & 409.27 & 1 & 409.27 & 15.13 & 0.0046 & Significant \\
B - Contact time & 2205.40 & 1 & 2205.40 & 81.52 & $<0.0001$ & Significant \\
$\begin{array}{l}\text { C - Initial } \\
\text { concentration }\end{array}$ & 3.20 & 1 & 3.20 & 0.12 & 0.7396 & Not significant \\
\hline
\end{tabular}

By referring to the Table 4, both contact time and $\mathrm{pH}$ were the significant model terms for the uptake response since the value of (Prob $>F$ ) $<0.05$. However, the effect of initial CIP concentration can be regarded as negligible since the $($ Prob $>$ F) value was found to be 0.7396 which is greater than 0.05 . Similar findings have been reported by a number of studies whereby the uptake of adsorbate molecules are more $\mathrm{pH}$ and contact time dependent. ${ }^{14,24,25}$ If the movement of the adsorbate molecules from the bulk liquid to the liquid film surrounding the adsorbent is ignored, the adsorption process onto a solid can be separated into three stages, as highlighted in the previous section. The occurrence of these three important phases resulted in contact time being one of controlling parameters in CIP uptake. The non-negligible effect of $\mathrm{pH}$ in the uptake of CIP is because the solution $\mathrm{pH}$ influences both of the degree of ionisation of the adsorbate molecules as well as the surface charge of the adsorbent.

In order to test the validity of the model, the function of desirability was applied. From Table 3, the percentage difference between the predicted uptake and the experimental uptake was in the range of $0.2 \%-5.2 \%$. The occurrence of these 
minimal deviations is most probably due to the contribution from the nonsignificant factors into the analysis.

\section{CONCLUSION}

In this study, GLP has demonstrated its effectiveness in the removal of CIP from aqueous solution. From FTIR analysis, the main functional groups that present on GLP were identified as $\mathrm{C}-\mathrm{H}, \mathrm{O}-\mathrm{H}, \mathrm{C}-\mathrm{O}$ and $\mathrm{C}=\mathrm{C}$. The surface morphology of GLP was studied using FESEM and AFM. Results revealed that the investigated adsorbent belongs to non-porous type materials. As from the AFM results, higher topography was observed in the AFM images after the adsorption process compared to the native GLP. Batch studies results shown that the adsorption was $\mathrm{pH}$ and contact time dependent. $\mathrm{pH} 4$ was identified as the optimum $\mathrm{pH}$ for the adsorption of CIP onto GLP. The rates of adsorption were rapid at the beginning, followed by a more gradual process and these were evidently shown within the studied range of concentrations. The results from kinetic study indicated that the removal of CIP using GLP follow closely the pseudo-second kinetic order model. The equilibrium data conform to both Langmuir and Freundlich isotherm models with high correlation coefficient of 0.9965 and 0.9981 , respectively. The maximum adsorption capacity $\left(\mathrm{q}_{\mathrm{m}}\right)$ was $232.56 \mathrm{mg} \mathrm{g}^{-1}$. From Plackett-Burman design, both $\mathrm{pH}$ and contact time were identified as the influential variables for CIP uptake. This finding was consistent with the results obtained from the batch studies. It is hoped that information gathered in this research project will provide an economical and efficient approach to remove antibiotics from the aqueous solution to avoid the development of antibiotic resistant bacteria.

\section{ACKNOWLEDGEMENTS}

The authors are thankful for the financial support and research facilities provided by Universiti Tunku Abdul Rahman, Malaysia.

\section{REFERENCES}

1. Cabello, F. (2006). Heavy use of prophylactic antibiotics in aquaculture: A growing problem for human and animal health and for the environment. Environ Microbiol., 8(7), 1137-1144, https://doi.org/10.1111/j.1462-2920.2006.01054.x.

2. Martinez, J. L. (2009). Environmental pollution by antibiotics and by antibiotic resistance determinants. Environ. Pollut., 157(11), 2893-2902, https://doi. org/10.1016/j.envpol.2009.05.051. 
3. Tambosi, J. L. et al. (2010). Recent research data on the removal of pharmaceuticals from sewage treatment plants (STP). Quim. Nova., 33(2), 411-420, https://doi. org/10.1590/S010040422010000200032.

4. Bhandari, A. et al. (2008). Occurrence of ciprofloxacin, sulfamethoxazole and azithromycin in municipal wastewater treatment plants. Pract. Period. Hazard. Toxic Radioact. Waste Manage., 12(4), 275-281.

5. Carmosini, N. \& Lee, L.S. (2009). Ciprofloxacin sorption by dissolved organic carbon from reference and bio-waste materials. Chemosph., 77(6), 813-820, https://doi.org/10.1016/j.chemosphere.2009.08.003.

6. Larsson, D. G. J., Pedro, C. \& Paxeus, N. (2007). Effluent from drug manufactures contains extremely high levels of pharmaceuticals. J. Hazard. Mater., 148(3), 751755, https://doi.org/10.1016/j.jhazmat.2007.07.008.

7. Rabia, R., Tariq, M. \& Maria, I. (2015). Brilliant green dye elimination from water using Psidium guajava Leaves and Solanum tuberosum peels as adsorbents in environmentally benign way. J. Chem., Article ID 126063, 1-9, https://doi. org/10.1155/2015/126036.

8. Kamsonlian, S. et al. (2012). Biosorption of arsenic from contaminated water onto solid Psidium guajava leaf surface: Equilibrium, kinetics, thermodynamics, and desorption study. Bioremed. J., 16(2), 97-112, https://doi.org/10.1080/10889868 .2012.665962.

9. Ravikumar, K., Deebika, B. \& Balu, K. (2005). Decolourization of aqueous dye solutions by a novel adsorbent: Application of statistical designs and surface plots for the optimization and regression analysis. J. Hazard. Mater., 122(1-2), 75-83, https://doi.org/10.1016/j.jhazmat.2005.03.008.

10. Rajendran, A., Thirugnanam, M. \& Thangavelu, V. (2007). Statistical evaluation of medium components by Plackett-Burman experimental design and kinetic modeling of lipase production by Pseudomonas fluoresceens. Ind. J. Biotechnol., 6, 467-478.

11. Myers, R. H., Montgomery, D. C. \& Anderson-Cook, C. M. (2009). Response surface methodology, 3rd ed. New York: John Wiley \& Sons.

12. Ojedokun, A. T.\& Bello, O. S. (2016). Kinetic modeling of liquid-phase adsorption of Congo red dye using guava leaf-based activated carbon. Appl. Water Sci., 7(4), 1965-1977, https://doi.org/10.1007/s13201-015-0375-y.

13. Lee, S. L., Liew, S. W. \& Ong, S. T. (2016). Experimental design approach for methylene blue dye removal in aqueous environment by nitrilotriacetic modified banana pith. Acta Chim. Slov., 63(1), 144-153, https://doi.org/10.17344/ acsi.2015.2068.

14. Gan, H. Y., Leow, L. E. \& Ong, S. T. (2017). Utilization of corn cob and $\mathrm{TiO}_{2}$ photocatalyst thin films for dyes removal. Acta Chim. Slov., 64(1), 144-158, https://doi.org/10.17344/acsi.2016.2983.

15. Peng, X. et al. (2015). Adsorption behavior and mechanisms of ciprofloxacin from aqueous solution by ordered mesoporous carbon and bamboo-based carbon. J. Coll. Interf. Sci., 460, 349-360, https://doi.org/10.1016/j.jcis.2015.08.050. 
16. Ngeno, E. C. et al. (2016). Adsorption of caffeine and ciprofloxacin onto pyrolitically derived water hyacinth biochar: Isothermal, kinetic and thermodynamic studies. J. Chem. Chem. Eng., 10, 185-194, https://doi.org/10.17265/19347375/2016.04.006.

17. El-Shafey, E. I., Al-Lawati, H. \& Al-Sumri, A.S. (2012). Ciprofloxacin adsorption from aqueous solution onto chemically prepared carbon from date palm leaflets. J. Environ. Sci., 24(9), 1579-1586, https://doi.org/10.1016/S1001-0742(11)609492.

18. Bajpai, S. K., Bajpai, M. \& Rai, N. (2015). Sorptive removal of ciprofloxacin hydrochloride from simulated wastewater using sawdust: Kinetic study and effect of pH. Water SA, 38(5), 673-682, https://doi.org/10.4314/wsa.v38i5.4.

19. Ho, Y. S. \& McKay, G. (1999). Pseudo-second order model for sorption processes. Process Biochem., 34(5), 451-465, https://doi.org/10.1016/S0032-9592(98)001125.

20. Lagergren, S. (1898). Zur theorie der sogenannten adsorption gel`ster stoffe. Kun. Sven. Vetenskaps. Handl., 24(4),1-39.

21. Jalil, M. E. R., Baschini, M. \& Sapag, K. (2015). Influence of pH and antibiotic solubility on the removal of ciprofloxacin from aqueous media using montmorillonite. Appl. Clay Sci., 114, 69-76, https://doi.org/10.1016/j. clay.2015.05.010.

22. Wang, Y. et al. (2015). Adsorptive removal of fluoroquinolone antibiotics using bamboo biochar. Sustain., 7(9), 12947-12957, https://doi.org/10.3390/su70912947.

23. Ponnusami, V., Srivastava, S. N.\& Vikram, S. (2008). Guava (Psidium guajava) leaf powder: Novel adsorbent for removal of methylene blue from aqueous solutions. J. Hazard. Mater., 152(1), 276-286, https://doi.org/10.1016/j.jhazmat.2007.06.107.

24. Ong, S. T. et al. (2015). Application of conventional and statistical experimental methodology to optimize malachite green dye removal from aqueous solutions. Desalin. Water Treat., 55(5), 1359-1371, https://doi.org/10.1080/19443994.2014 .925830 .

25. Ong, S. T. \& Seou, C. K. (2014). Removal of reactive black 5 from aqueous solution using chitosan beads: optimization by Plackett-Burman design and response surface analysis. Desalin. Water Treat., 52, 7673-7684, https://doi/ 10.1080/19443994.2013.830684 